\title{
Alargar a Concepção de Ciência é Construir Pontes ou Abismos? Sobre a Filosofia da Ciência de Passeron
}

[Enlarging the Conception of Science is to Build Bridges or Chasms? On the Philosophy of Science of Passeron]

\section{Juliana de Orione Arraes Fagundes ${ }^{\sqrt{*}}$}

\begin{abstract}
Resumo: Neste trabalho será discutida a distinção feita pelo filósofo francês Jean-Claude Passeron entre as ciências históricas e as ciências naturais. Passeron observa que os critérios do normativismo de Popper não podem ser aplicados às ciências sociais e aponta distinções profundas entre elas e as ciências naturais. Nesse sentido, propõe um alargamento da concepção de ciência empírica para que as ciências sociais sejam incluídas. Porém, em uma crítica a Passeron, este trabalho objetiva argumentar que ciências da natureza e humanas compartilham de dificuldades e soluções epistemológicas, não estando tão distantes. Além disso, será proposto aqui que a mesma realidade se sujeita a diferentes descrições, a partir das diversas disciplinas. Espera-se, com isso, sugerir que a inclusão das ciências humanas no rol das ciências empíricas tenha uma abordagem mais simples do que tem parecido a Passeron.
\end{abstract}

Palavras-chave: Passeron. Epistemologia das Ciências Humanas. Popper.

\begin{abstract}
This work will discuss the distinction made by the French philosopher Jean-Claude Passeron between the historical sciences and the natural sciences. Passeron stresses that the rules of Popper's normativism cannot be applied to social sciences and highlights profound distinctions between them and the natural sciences. For this reason, he suggests to enlarge the conception of empirical science, so that it could also include social disciplines. However, from the perspective of a broader evaluation of Popper, this paper tries to show that natural and social sciences face common epistemic difficulties and solutions, thus, they should not be considered so distant. In addition, it intends to look to another possibility of approaching the question: accepting that there are many ways to describe the same reality. Perhaps the way to qualify social sciences as truly scientific is simpler than it has seemed to Passeron.
\end{abstract}

Keywords: Passeron. Epistemology of Human Sciences. Popper.

\footnotetext{
${ }^{*}$ Agradeço ao Grupo de Escrita Mulheres na Filosofia (GEMF) pela avaliação e discusão que fizeram de uma versão prévia deste trabalho.

${ }^{*}$ Professora da Universidade Estadual de Santa Cruz (UESC). Doutora em Filosofia pela Universidade Federal da Bahia (UFBA). E-mail: julianadeorione@hotmail.com. ORCID: https://orcid.org/0000-0002-9823-5910.
} 


\section{Introdução}

Preocupado em estabelecer o lugar das ciências humanas entre as demais ciências, Passeron (1995) pensa ser necessário compreender o termo "ciência" de forma ampla. Por terem características espaço-temporais muito definidas, as ciências humanas são chamadas por ele de "ciências históricas". No caso das ciências históricas, há diversas possibilidades metodológicas dentro da sociologia, da antropologia, da própria história, assim sucessivamente. Isso se deve ao caráter altamente contextual dessas disciplinas. Por isso, não seria possível nesses casos o estabelecimento de um paradigma, no sentido de Kuhn $\bigsqcup^{1}$ (1998), ou de um programa de pesquisa, no sentido de Lakatos2 (1977), onde a ciência possa crescer em produção de conhecimento a partir de certos fundamentos estáveis durante um período. Também não seria possível, na concepção do autor, enquadrar as ciências históricas dentro dos padrões do falsificacionismo popperiano, dadas as especificidades dessas disciplinas em comparação com as ciências naturais.

As ciências históricas e as ciências naturais, segundo o autor, possuem características muito distintas. Enquanto estas podem almejar alguma universalidade, aquelas estão sempre localizadas espaço-temporalmente. Isso acabaria por provocar também uma diferença linguística entre os dois campos. As ciências naturais, de acordo com o autor, poderiam abdicar da linguagem natural valendo-se dos simbolismos formais em suas construções teóricas e modos de testar. Porém, para as ciências humanas, isso não seria possível. Essas diferenças entre as ciências históricas e as ciências naturais, para Passeron, levam à necessidade de se formular uma concepção de ciência que abarque todas as disciplinas.

Passeron ilumina importantes aspectos das ciências sociais ao mostrar que as mais proeminentes filosofias das ci-

\footnotetext{
${ }^{1}$ Para que se forme um paradigma no sentido de Kuhn, é preciso o estabelecimento de um acordo entre a comunidade científica envolvida numa disciplina. Esse acordo inclui o uso dos termos de maneira suficientemente unificada para que a ciência possa "progredir". O problema das escolas individuais nas ciências humanas, segundo Kuhn, é que elas discutem constantemente os fundamentos umas das outras (1998, p. 204), o que impede a formação do paradigma e torna impossível o progresso. Contudo, a noção de progresso é, para ele, requisito para uma disciplina ser considerada científica. Ele compara as ciências humanas ao que nas "ciências maduras" (isto é a terminologia de Kuhn para aquelas que estabelecem paradigmas) seria chamado de fase pré-paradigmática: uma fase em que os fundamentos não estão ajustados e há um grande debate entre os pesquisadores daquela área para poder estabelecê-los.

${ }^{2}$ De acordo com Leclerc (2008, p.5): “Um programa de pesquisa é um conjunto de regras metodológicas prescrevendo caminhos a percorrer (heurística positiva) e os caminhos a evitar (heurística negativa). Um programa de pesquisa é constituído de um Núcleo Duro, um conjunto de princípios teóricos intocáveis que determina sua identidade, e de um Cinturão de Proteção, um conjunto de hipóteses ou teorias auxiliares que protegem o Núcleo Duro contra falsificação, digerem anomalias, respondem a objeções, etc. A aceitação dos princípios do Núcleo Duro obriga os pesquisadores a rejeitar qualquer hipótese ou teoria que contradiz esses princípios, e a promover hipóteses ou teorias auxiliares para facilitar a aplicação deles, ou para complementá-los, desenvolvê-los de modo progressivo no sentido de uma maior adequação empírica". A proposta de Lakatos ressalta o aspecto conservador dos programas de pesquisa. O Núcleo Duro permanece estável, ainda que possa haver ajustes no Cinturão de Proteção para coordenar as relações entre o programa de pesquisa e o confronto com a realidade. Embora haja importantes diferenças entre os pensamentos dos dois autores, assim como Kuhn, Lakatos defende a necessidade de uma base relativamente estável sobre a qual uma comunidade científica precisa se assentar para poder desenvolver suas pesquisas.
} 
ências, como a de Popper e a de Kuhn, deixam de fora grande parte do conhecimento atualmente produzido, isto é, o das ciências históricas. No caso das ciências sociais, como bem aponta o autor, a indexicalidade ${ }^{3}$ está presente como fator fundamental sem o qual não é possível sequer iniciar uma pesquisa histórica. Porém, a questão que pretendemos colocar a Passeron é: Essas diferenças entre as disciplinas são tão profundas a ponto de isolar completamente o campo das ciências históricas e o das ciências naturais? O problema dos argumentos do autor é que eles afastam as disciplinas, dificultando a tarefa de considerá-las todas como pertencentes ao mesmo estilo de saber: o conhecimento científico. Este trabalho argumentará que as fronteiras entre ciências naturais e ciências sociais não podem ter um traçado nítido, as disciplinas estão mais próximas do que parecerem.

Alguns argumentos serão apresentados para mostrar a proximidade entre as ciências humanas e as naturais maior do que pareceria a Passeron. Para isso, apresentaremos brevemente o falsificacionismo seguido da crítica em que Passeron mostra que o normativismo pop- periano não pode ser usado na avaliação das ciências históricas. Argumentaremos, a partir daí, que essa é uma crítica ampla e não se restringe apenas a algumas disciplinas científicas. Na medida em que a crítica se estende tanto às ciências físicas e naturais quanto às ciências humanas, ela não permite uma diferenciação entre as disciplinas diversas.

Em seguida, apresentaremos e criticaremos o argumento de Passeron de que o simbolismo usado nas ciências naturais seria formal, ao passo que as ciências históricas admitiriam apenas a linguagem natural. Nesse ponto, tentaremos mostrar que a diferença entre as disciplinas no uso das ferramentas simbólicas é apenas de grau, de modo que elas estão mais próximas do que pareceria.

O terceiro argumento que será usado para aproximar as diversas disciplinas é de que a biologia contém características intermediárias entre ciências naturais e ciências históricas. Nesse sentido, organizando-se as diversas disciplinas com seus respectivos sistemas simbólicos e teóricos, elas poderão ser compreendidas de modo mais aproxi-

\footnotetext{
${ }^{3}$ Indexicalidade é um termo em filosofia da linguagem para situações nas quais o significado de uma sentença depende de seu contexto de proferimento, incluindo as pessoas envolvidas na comunicação, o local e o momento (HUANG, 2015). Também conhecidos como dêiticos, são exemplos de termos indexicais: "eu" (depende da pessoa que fala); "aqui", "este" (dependem do local); "agora", amanhã" (dependem do momento). Nesse sentido, as ciências históricas estão sempre ancoradas no contexto. Granger (apud LACOUR, 2012) apresenta para as linguagens naturais condições protológicas - quais sejam, pluralidade de articulação, função de enunciação completa, ancoragem, nomes próprios e distinção tema/rema (sobre o que se fala e o que se fala) -, necessárias para que elas cumpram sua dupla função de simbolização e comunicação. Assim, as linguagens naturais contam com diversos recursos dêiticos que os sistemas formais, por suas características (delimitação semântica inequívoca, conjunto fechado de símbolos e restrições na concatenação dos símbolos), não possuem. Por isso, tanto Granger quanto Passeron consideram a língua natural indispensável na pesquisa histórica.
} 
mado umas das outras, o que facilitaria a busca de uma compreensão ampla de ciência.

\section{O normativismo de Popper}

O subtítulo do livro de Passeron é "O espaço não-popperiano do raciocínio natural". Em sua defesa da cientificidade das chamadas ciências históricas, ele se dedica a mostrar que elas jamais poderiam ambicionar o cumprimento do critério de Popper para a cientificidade. Nesse ponto, Passeron traça uma linha divisória entre as ciências naturais e as históricas: estas não poderiam ser avaliadas de acordo com os critérios de Popper.

A filosofia da ciência de Popper é normativista. Ele dá à filosofia o papel de legislar e estabelecer um critério de demarcação entre o que é ciência e o que não é. O critério para uma teoria ser considerada científica é que, em confronto com a experiência, ela possa ser falsificada. Chalmers (1993, p. 66-67), ao explicar o falsificacionismo, afirma: "Há uma condição fundamental que toda hipótese ou sistema de hipóteses deve satisfazer para ter garantido o status de lei ou teoria científica. Para fazer parte da ciência, uma hipótese deve ser falsificável".

Uma teoria é considerada falsificável se é logicamente possível uma proposição de observação que a contradiga. Um exemplo oferecido por Chalmers: "quando um raio de luz é refletido de um espelho plano, o ângulo de incidência é igual ao ângulo de reflexão" (1993, p. 67). Há grandes chances de que essa proposição seja verdadeira, mas há a possibilidade lógica de que uma proposição de observação a contradiga, basta que o ângulo de reflexão seja diferente do previsto em uma observação. Por outro lado, uma proposição tautológica como "o quadrado possui quatro ângulos internos" não é falsificável. Uma vez que estamos diante da própria definição de quadrado, nenhuma situação de observação poderia contradizê-la.

Com esse critério, Popper pretende trazer às ciências a confiabilidade dos procedimentos dedutivos, uma vez que a indução pode sempre falhar. A indução nunca carrega consigo o estatuto de certeza dos procedimentos dedutivos. O método dedutivo consiste em extrair das premissas aquilo que já estava implícito nelas 4 . Se há uma hipótese geral e ela encontra na realidade um contraexemplo, isso significa que a hipótese é falsa. As teorias científicas, segundo essa concepção, precisam ser desenha-

\footnotetext{
${ }^{4}$ Aqui, estamos usando o termo "dedução" no sentido lógico, forte, conforme apresentado na nota anterior. Há outros sentidos para o termo dedução. Por exemplo, "no sentido derivativo epistemológico de Kant, uma dedução é um argumento que objetiva justificar o uso de um conceito, o que demonstra que o conceito pode ser corretamente aplicado a objetos" (PEREBOOM, 2014). Dedução, nesse sentido, pode ser um argumento sintético, que acrescenta algo às premissas. Não é esse o sentido de Popper nem o sentido que estamos tratando aqui, estamos tratando de dedução lógica.
} 
das de tal maneira que haja uma possibilidade lógica de falsificação. Elas não podem ser tautologias, uma vez que as tautologias, por princípio, não podem ser falsificadas e também não podem ser mero resultado de induções rápidas e ingênuas. No mais, quanto maiores forem as perspectivas de falsificação de uma teoria, melhor ela é. O trabalho científico se caracterizaria por colocar as teorias à prova de maneira tenaz.

Ora, se as teorias científicas se caracterizam pela falsificação, então como poderíamos dizer que elas carregam consigo algum grau de certeza? Na realidade, a certeza só surge quando uma teoria é de fato falseada e deixa de fazer parte do corpo das teorias científicas. Na concepção de Popper, dada uma teoria, a corroboração pela observação irá torná-la mais firme e robusta, mas nunca definitivamente comprovada. "Importa acentuar que uma decisão positiva só pode proporcionar alicerce temporário à teoria, pois subsequentes decisões negativas sempre poderão constituir-se em motivo para rejeitá-la" (POPPER, 2008, p. 34). Porém, quando uma observação a refutar, a teoria deve ser definitivamente abandonada e substituída por outra.

"Minha posição está alicerçada em uma assimetria que decorre da forma lógica dos enunciados universais. Estes enunciados nunca são deriváveis de enunciados singulares, mas podem ser contraditados pelos enunciados singulares" (POPPER, 2008, p. 43). Em outras palavras, a ideia de Popper é que o cientista formula primeiramente hipóteses, apresentadas em forma de enunciados universais, em seguida, parte em busca de enunciados particulares de observação capazes de refutá-los. Além disso, diante de uma observação falsificadora de uma teoria, Popper proíbe a formulação de hipóteses auxiliares ad hoc para resguardar a teoria, quer dizer, a hipótese não pode ser reformulada para acolher as anomalias. Ela deve ser definitivamente abandonada.

Popper estabelece critérios rigorosos e claros para delimitar o que seja ciência ou não. Cabe perguntar, contudo, se as comunidades de cientistas realmente estruturam suas pesquisas a partir desses critérios. $\mathrm{Na}$ concepção de Passeron, os critérios popperianos foram pensados tendo como foco as ciências da natureza, mas não servem às ciências históricas. São duas as razões principais: em primeiro lugar, ele considera que a normatividade é uma ilusão à qual as ciências históricas não podem se adequar. Em segundo lugar, não é possível construir proposições nomologicamente universais ${ }^{5}$ nas ciências humanas para tentar falsificá-las a partir da observação. Como dito, a carac-

\footnotetext{
${ }^{5}$ Há uma distinção entre universalidade nomológica e universalidade numérica. Segundo Passeron, enquanto as ciências naturais podem construir universais nomológios, as ciências históricas poderiam construir, no máximo, universais numéricos, insuficientes para aplicação do falsificacionismo.
} 
terística da indexação, constituinte das ciências históricas, impede que suas teorias se descolem das situações concretas. Isso cria a necessidade de novos debates tanto sobre léxico quanto sobre métodos a cada nova situação. Então, ao mesmo tempo em que isso impede a formulação de hipóteses falsificáveis, impede também a elaboração de possíveis experimentos supostamente capazes de falsificá-las.

\subsection{Nenhuma das proprieda-} des lógicas que tornam possivel a refutabilidade 6 ("falsifiability") de uma proposição teórica pertence stricto sensu às que compõem uma teoria sociológica, pelo simples fato de que o sentido da informação sobre o qual fazem uma asserção continua sempre solidária em relação a uma série de configurações históricas singulares. (PASSERON, 1995, p. 429, grifado no original)

De fato, se as proposições são mais falseáveis quanto mais gerais, e as proposições das ciências sociais são sempre formuladas sobre lugares e momentos específicos, então elas perdem a possibilidade de se submeterem à falsificação. As hipóteses ad hoc, proibidas pelo falsificacionista, são uma cons- tante aqui, pois o que se quer compreender está localizado historicamente. Ainda que existam proposições relativamente gerais nas ciências históricas, elas nunca são universais e por isso não podem se sujeitar ao falsificacionismo.

Popper realmente estabelece que os enunciados das ciências devem ser universais no sentido estrito do termo, o que excluiria as ciências humanas do estatuto de ciência. Passeron observa que Popper faz uma diferenciação entre universalidade nomológica (ou estrita) e universalidade numérica (ou enumerativa). A primeira diz respeito aos enunciados que se pretendem verdadeiros "não importa em relação ao quê e a que momento" (PASSERON, 1995, p. 430) e a segunda se refere aos enunciados que, embora gerais, se restringem a "uma classe finita de elementos especificados numa região espaçotemporal particular e limitada" (PASSERON, 1995, p. 430). Então, um dos critérios de Popper é que a proposição seja universal no sentido nomológico, mas as ciências humanas jamais poderão se sujeitar a isso.

Tendo em vista a situação metodológica referida, considero útil e frutífero encarar as leis naturais como enunciados sintéticos e estritamente univer-

\footnotetext{
${ }^{6} \mathrm{O}$ tradutor do livro de Passeron prefere o termo "refutabilidade" a "falsificabilidade". Neste trabalho, preferimos "falsificabilidade", pois temos visto este termo ser mais comumente associado ao trabalho de Popper tanto nas traduções quanto nos comentários. Portanto, o leitor pode considerar, aqui, "refutabilidade" e "falsificabilidade" como sinônimos.
} 
sais ("enunciados-todos"). Isso equivale a encará-los como enunciados não verificáveis, que podem ser apresentados sob a forma seguinte: "de todos os pontos do espaço e do tempo (ou em todas as regiões do espaço e do tempo) é verdadeiro que...". Em contraste, chamo de enunciados "específicos" ou "singulares" os enunciados que dizem respeito apenas a certas regiões finitas do espaço e do tempo. (POPPER, 2008, p. 66, aspas internas do original)

Passeron mostra a impossibilidade de adequação das ciências históricas ao falsificacionismo e, ao mesmo tempo, defende a cientificidade desses estudos que são localizados espaçotemporalmente e vinculados a análises multifocais da realidade humana. Porém, é possível que os critérios impostos por Popper não consigam subjugar a metodologia científica de forma nenhuma, nem no que diz respeito às ciências históricas nem às demais ciências.

\section{Teoria e observação}

Nos fundamentos da epistemologia de Passeron, encontramos uma objeção ao falsificacionismo que talvez se estenda a todas as ciências, inclusive às ciências naturais. Essa é uma objeção já bastante conhecida. Ao pensar sobre as condições de funcionamento das ciências empíricas, o autor as apresenta como "linguagens de descrição do mundo que devem produzir um tipo particular de conhecimento para as provas empíricas que a estrutura lógica dessas linguagens torna possíveis e necessárias" (PASSERON, 1995, p. 399). Porém, para que o falsificacionismo funcionasse, seria necessário haver uma independência entre as observações e a teoria submetida a teste. Mas como apresentado pelo próprio Passeron na primeira proposição recapitulativa de seu livro sobre filosofia da ciência, há conceitos e teorias anteriores às observações que determinam o método apropriado para a busca de provas empíricas. Assim, as observações não têm independência em relação à teoria. Ao contrário, as observações são guiadas pela teoria, de tal maneira que a pretensão do falsificacionista de abandonar a teoria diante de uma observação que a contradiga não se realiza na prática.

Os "enunciados de base" mais próximos da percepção natural contém a teoria, no sentido em que seu sentido assertórico jamais é autossuficiente, sendo sempre, por um lado, devedores deste sentido a uma linguagem de descrição do mundo, que este seja construído por um discurso científico ou praticado espontaneamente no qua- 
dro pré-construído de uma cultura ou de uma linguagem costumeira (PASSERON, 1995, p. 401).

Conforme Chalmers: "Não é preciso muita argumentação para demonstrar que há teoria considerável pressuposta na asserção: 'O facho eletrônico foi repelido pelo polo norte de magneto', ou pelo diagnóstico de um psiquiatra dos sintomas de abstinência de um paciente". Ele continua: "Proposições de observação [...] são sempre feitas na linguagem de alguma teoria e serão tão precisas quanto a estrutura teórica ou conceitual que utilizam" (1993, p. 54). Uma vez que as observações são invariavelmente orientadas por teorias anteriores, elas podem se equivocar a partir de equívocos na própria teoria sendo, portanto, frequentemente enganadoras quanto ao seu potencial falsificador. Um exemplo de Chalmers:

[...] alguns participantes de um piquenique no topo de uma alta montanha, dirigindo seus olhares à fogueira, podem observar: "A água está suficientemente quente para fazer o chá", e descobrir então que infelizmente estavam errados ao experimentarem a bebida resultante. A teoria, erroneamente suposta, foi a de que água fervente é quente o suficiente para se fazer chá. Este não é necessariamente o caso para água fervente sob as pressões baixas experimentadas em grandes altitudes.

Nesse ponto, parece que todas as disciplinas estão no mesmo barco frente ao falsificacionismo: as observações pressupõem uma série de teorias anteriores, de modo que o processo de falsificação se torna equívoco diante das características reais das ciências. No fim das contas, o argumento de Passeron de que a observação contém a teoria é um ataque amplo ao falsificacionismo, e não apenas à possibilidade de aplicação do falsificacionismo às ciências históricas.

\section{O simbolismo natural e o formal}

Como mencionado, Passeron não concorda com o critério que estabelece a necessidade de um paradigma relativamente estável para uma disciplina ser considerada científica. Ele afirma que o uso de uma linguagem formalizada seria necessário para a formação de um paradigma científico, mas não é possível estabelecer esse acordo nas chamadas ciências históricas porque elas possuem um grau muito maior de contextualização. A necessidade de especificação das condições espaçotemporais nessas ciências torna impossível formalizá-las. Há, segundo ele, uma característica insuperável nas ciências históricas: não permitem estabelecer um vocabulário estável que sirva 
de fundamento à formação de um paradigma. Diante dessa dificuldade, a própria concepção de ciência deve ser revista, pensa Passeron.

Como temos visto, um ponto importante no trabalho do autor é seu esforço por defender as ciências humanas dos ataques do falsificacionismo de Popper $(2008 ; 1980)$. Passeron argumenta que elas não se sujeitam ao falsificacionismo não por serem pseudociências, mas porque a aplicação do método de Popper exigiria o uso de um simbolismo artificial, incapaz de capturar todas as sutilezas das ciências históricas. Por sua enorme flexibilidade comunicativa, apenas a linguagem natural, segundo Passeron, pode ser apropriada para a maior parte dos procedimentos das ciências históricas. Então, se é verdade que o procedimento de falsificação exige um simbolismo artificial, as ciências históricas jamais poderão adotá-lo.

As palavras de descrição da língua conceitual do mundo histórico devem às operações do raciocínio natural que define seu campo semântico o fato de, para serem compreendidas pelo interlocutor, referirem-se ao mesmo tempo a ocorrências datadas e localizadas (a "casos" históricos objetos de simples designação) e a listas ou combinações de propriedades genéricas que dependem de uma "descrição definida". Contudo, nenhuma descrição definida que enumere as propriedades econômicas, jurídicas, mentais, políticas, militares, etc. pode, sozinha, transmitir o sentido da palavra "feudalismo" a um leitor que ignorasse a existência do Ocidente medieval, da China dos Reinos Combatentes, o Japão da era Kamakura, etc. (PASSERON, 1995, p.433)

De fato, as linguagens naturais são altamente abrangentes em suas possibilidades semânticas. Por mais que tenham como vantagem a facilitação dos cálculos e precisão do vocabulário, os simbolismos formais são semanticamente empobrecidos e rígidos demais para abrangerem a multiplicidade expressiva das linguagens naturais. Portanto, ainda que seja possível formalizar uma série de proposições nas mais diversas disciplinas, inclusive nas ciências históricas (por exemplo, parte da estatística), o lar do raciocínio sociológico é o mesmo do raciocínio de cada ser linguístico: a linguagem natural.

Ao afirmar que a maior parte das nossas possibilidades expressivas só existe na linguagem natural, Passeron chama a atenção para essa simples realidade: As formalizações fazem sentido por sua utilidade e são úteis quando permitem a simplificação dos cálculos. Convém, portanto, trabalhar na riqueza expressiva das linguagens naturais e, só a par- 
tir daí, quando útil, utilizar as formalizações.

Contudo, ao atribuir às ciências da natureza o espaço da formalização, Passeron parece restringi-las demais, como se a formalização fosse seu único recurso. Em outras palavras, Passeron parece introduzir uma distinção muito forte entre ciências naturais e ciências humanas baseada em simbolismos distintos.

A verdade de uma proposição é dada pelas suas condições de verdade, ou seja, entender uma proposição é conhecer em que condições ela pode ser verdadeira. Tarski (apud Gómez-Torrente, 2015) oferece uma definição semântica de verdade para as linguagens formais segundo a qual o significado de uma proposição escrita em uma linguagem formal não pode ser dado dentro da própria linguagem, é necessário recorrer a uma metalinguagem 7 . Se essa ideia está correta, as linguagens formais não possuem sentido por si mesmas, necessitam de uma compreensão que lhes é dada a partir de outra linguagem. Porém se essa compreensão for dada também em uma linguagem formal, não corremos o risco de regredir ad infinitum? Conforme argumentado pelo próprio Passeron: "Não se pode casar língua natural e língua artificial sem designar à dupla um dono da casa, uma meta-língua de suas relações" (1995, p. 422). Por isso será sempre necessário, em algum momento, que se recorra à linguagem natural para a compreensão de um simbolismo formal. Em outras palavras, todo simbolismo formal carece de sentido se não houver para ele uma interpretação dada em metalinguagem. Isso se daria em qualquer situação, independente de estarmos ou não diante de uma linguagem científica.

A perspectiva de simplificação linguística trazida pela formalização, contudo, é o que a torna importante em diversas ciências. Com isso, os simbolismos formalizados se tornam extremamente poderosos e permitem trabalhar questões altamente complexas que se tornariam obscuras e difíceis demais se fossem trabalhadas nas linguagens naturais. Fora isso, é provável que não haja um motivo mais fundamental ou um espaço linguístico essencialmente reservado para certas disciplinas e não para outras, há apenas uma diversidade de recursos linguísticos e explicativos aos quais podemos recorrer em diferentes momentos, tanto nas ciências da natureza quanto nas ciências humanas.

Conforme apontado por Arruda (2005), na mesma direção argumentativa, os sistemas formais dependem de

\footnotetext{
${ }^{7}$ Tentar definir a verdade para uma linguagem formal a partir dessa mesma linguagem dá origem a paradoxos semânticos como o do mentiroso. O paradoxo se expressa, por exemplo, por meio da proposição "Esta proposição é falsa", que será falsa se for verdadeira e verdadeira se for falsa. De acordo com Tarski, esse paradoxo pode ser evitado se compreendemos que o predicado de verdade pertence a uma linguagem semanticamente superior, ou seja, uma metalinguagem. A partir de uma metalinguagem, é possível descrever a verdade em uma linguagem de nível inferior, a linguagem-objeto.
} 
uma interpretação que lhes é dada em linguagem natural. Em outras palavras, as expressões de um sistema formal, isoladamente, carecem de significado. Por isso, é possível defender que não há uma diferença radical de simbolismo entre as ciências naturais e as ciências históricas, embora seja importante reconhecer a maior necessidade das ciências naturais recorrerem aos simbolismos formais. A diferença é de grau, não é uma diferença de tipo. Convém também reconhecer que o espaço da linguagem natural nas ciências humanas, justamente pelo alto grau de indexicalidade exigido aqui, é mais vital do que nas exatas. Porém, da mesma maneira como os simbolismos formais podem ser instrumentos para as ciências naturais, podem também servir de instrumentos para as ciências históricas. Por exemplo, o raciocínio estatístico pode ser útil tanto nas pesquisas em sociologia quanto em genética, embora de formas distintas.

Mesmo a filosofia, como nos lembra Leclerc (2009), também se serviu de linguagens formalizadas em diversas investigações, em especial, na filosofia analítica. Além disso, as condições de verdade de suas proposições são determinadas por meio de uma interpretação feita em linguagem natural. É preciso reconhecer, porém, que uma vez feita essa interpretação de uma linguagem formal, pode haver um descolamento do contexto, ao contrário das linguagens naturais, nas quais muitas propo- sições só fazem sentido dentro de um contexto. Então, o formalismo linguístico, além de depender das linguagens naturais, não parece caracterizar um tipo específico de investigação científica, mas ser um recurso amplamente disponível para qualquer busca cognitiva humana. É certo que Passeron traz uma contribuição importante ao insistir no papel das linguagens naturais para o raciocínio sociológico, mas isso não é suficiente para caracterizar uma diferença real entre ciências da natureza e ciências históricas, apenas uma diferença de grau.

\section{A biologia: uma zona nebulosa}

Não é nosso objetivo tentar propor um critério de demarcação, mas apenas argumentar que a realidade pode ser descrita de diversas formas e a partir de diversos ângulos, o que não cria abismos entre as ciências naturais e as ciências humanas. Por vezes, os mesmos recursos de umas podem ser aplicados a outras. Dependendo do fenômeno a ser explicado, um tipo de abordagem será mais apropriado. As diversas disciplinas científicas nos trazem instrumentais teóricos variados e ricos para procedermos nossas descrições da realidade a partir de múltiplas perspectivas. Obviamente, pensar a realidade a partir de um instrumental da física não nos traria nenhuma informação relevante sobre uma audiência em um tri- 
bunal, por exemplo. As diferentes possibilidades de descrição, contudo, não se anulam, mas podem ser sobrepostas. Essa certamente não é uma perspectiva incompatível com as ideias de Passeron, mas apenas uma aproximação diferente a partir da qual, pensamos, os abismos entre as disciplinas deixariam de existir.

À medida que nos aproximamos mais das complexidades culturais e históricas da existência humana, o vocabulário se torna mais complexo e a necessidade de indexação é maior. Porém, é possível que isso não se construa de maneira tão abrupta, e sim, gradualmente. É provável, por exemplo, que a biologia tenha aspectos muito mais indexicalizados do que Passeron percebe. Nesse sentido, a biologia parece uma disciplina intermediária que preenche possíveis lacunas entre ciências humanas e exatas.

Conforme Dennett (1998), o processo evolutivo no mundo natural do qual somos parte poderia ser descrito de maneira abstrata como um algoritmo $0^{8}$ que entra em funcionamento desde que três condições sejam dadas: variação, retenção e seleção. É preciso, portanto, que haja uma abundância de elementos di- ferentes entre si (variação), que cada uma dessas variantes seja capaz de produzir cópias de si mesmas (retenção) - ainda que às vezes ocorram erros de cópia (é isso que gera a variação) - e que algumas dessas variantes tenham mais propensão a se reproduzir do que outras (seleção) 9 . Se pensarmos em organismos muito simples, por exemplo, a seleção é feita pelo ambiente em que eles vivem. É o ambiente que pode permitir a reprodução ou não daquele organismo em situações muito específicas. Por isso, dizemos que o processo é local, cego e contingente. No mais, para se compreender uma característica adaptativa de um ser vivo, é preciso saber as condições históricas e o ambiente específico em que aquela característica evoluiu.

Por exemplo, nós vivemos em um ambiente cultural com oferta abundante de açúcar e gordura. Ao mesmo tempo, temos o paladar bastante inclinado a esses nutrientes e tendemos a consumi-los em excesso. Isso nos provoca problemas de saúde altamente disseminados nas sociedades ocidentais, tais como diabetes e colesterol alto. Porém, nossa espécie provavelmente evoluiu em um ambiente pobre em açúcar

\footnotetext{
${ }^{8}$ Um algoritmo, segundo ele, é um mecanismo simples, que funciona por meio de pequenos passos destituídos de uma inteligência subjacente, que pode ocorrer em diferentes substratos e pode ter o poder de gerar grandes resultados (DENNETT, 1998). Por exemplo, um cálculo matemático é realizado por meio de um passo-a-passo determinado que pode ser realizado por uma máquina de calcular, um ábaco, uma pessoa com um papel e um lápis etc. Um algoritmo pode ter etapas aleatórias, o que torna seus resultados imprevisíveis. É o caso do algoritmo evolutivo. É importante ressaltar que um algoritmo não precisa necessariamente de um simbolismo formal para rodar. Muitas vezes, um processo de ocorre de maneira caótica em uma mente pode ter o mesmo resultado de um processo organizado ocorrendo em um computador. Uma receita de bolo pode ser considerada um algoritmo em linguagem natural.

${ }^{9}$ Campbell (1960), Popper (1992) e o próprio Dennett (1998) defendem que esse algoritmo ocorre sucessivas vezes em diferentes substratos, inclusive no próprio desenvolvimento da ciência, mas aqui estamos tratando apenas de sua aplicação à biologia.
} 
e gordura no período Pleistoceno. Naquele ambiente, tínhamos grande necessidade desses nutrientes para podermos sobreviver e nos reproduzir, e nossos ancestrais que gostavam de açúcar e gordura foram favorecidos. Com isso, até hoje nós carregamos essa característica, ainda que ela não nos sirva mais. Isso mostra que o processo evolutivo é altamente contextual e contingente.

Como colocado por Gould e Lewontin (1979), a seleção natural não tem como efeito sempre a melhor adaptação ao ambiente. Pode ser uma adaptação simplesmente satisfatória, ou mesmo um efeito secundário de adaptações ocorridas em ambientes bem específicos. Nesse sentido, podemos dizer que os eventos evolutivos são indexicalizados, pois ocorrem sempre com hora e local definido. As variantes envolvidas são tantas que não é possível reproduzilas para obter novamente o mesmo processo. Uma sequência de acasos deu origem aos seres que somos. Não há, aqui, previsibilidade nem teste empírico de hipóteses específicas.

No ambiente cultural e histórico, essa situação se repete, embora com um grau de complexidade muito maior. Observamos, aqui, que tanto para a o processo evolutivo orgânico quanto para o estudo das ciências humanas vale: os eventos ocorrem com hora e lugar específicos e há uma multiplicidade de fatores envolvidos, impossibilitando a realização de experimentos que possam repetir essa multiplicidade de fatores ${ }^{10}$. Diante disso, podemos concluir que há mais aproximações entre a biologia e as ciências históricas do que pareceria à primeira vista.

Lacour chama a atenção para uma sutileza epistemológica que aproxima as ciências humanas e aqui podemos encará-la como algo que também relaciona o humano e o natural: o "conhecimento clínico". "Este se pode definir como saber interpretativo das singularidades, não reduzível ao domínio medical, pois joga um papel crucial em cada ciência humana" (LACOUR, 2016, p. 1). Uma série de aspectos altamente indexicalizados devem ser levados em consideração para que o médico possa ter um conhecimento preciso de seu paciente, que é um indivíduo, e de seus sintomas. É preciso colher informações sobre os diversos hábitos daquele paciente, se ele pratica ou não esportes, como se alimenta, quais doenças já desenvolveu, quais doenças seus pais tiveram, se dorme bem, se é fumante etc.

Da mesma forma, os eventos históricos só podem ser compreendidos a partir de diversos aspectos relevantes e absolutamente singulares. Está claro, portanto, a relevância do conhecimento clínico nas ciências humanas e na me-

\footnotetext{
${ }^{10}$ No caso da biologia, é possível realizar experimentos em condições artificiais, isolando fatores. Isso ajuda na compreensão dos eventos, mas não trará deles um quadro completo.
} 
dicina. Mas, como vimos, há aspectos também locais na compreensão da evolução dos organismos. Aparentemente, portanto, o conhecimento clínico também pode ser relevante aqui, embora em menor grau. Assim, é possível que os recursos explicativos das diversas disciplinas sejam ferramentas úteis umas às outras, podendo, muitas delas, serem emprestadas de uma disciplina por outra.

\section{Níveis de descrição da realidade}

Como mencionamos, há diversas maneiras pelas quais podemos descrever a realidade e cada uma delas será apropriada para descrever aspectos específicos do mundo. Com um microscópio, é possível ver de perto como são as hemácias e os neurônios, desenvolvendo conhecimentos bastante relevantes sobre essas células. Por outro lado, se alguém tentar usar um microscópio para ler um romance, estará fazendo algo sem sentido algum. No caso do romance, é necessário haver outro tipo de relação com o mundo objetivo. Assim, a tentativa de compreender os métodos das ciências em geral a partir do método de alguma ciência específica fracassará, pois trará um recorte empobrecido demais da realidade. Não é possível tratar da sociologia com os métodos da física simplesmente porque as duas disciplinas lidam com aspectos distintos da nossa epistemologia. Temos múltiplas possibilidades de olhar para a realidade, donde decorrem múltiplas possibilidades de descrevê-la.

A dificuldade em aceitar as diversas disciplinas científicas como diversos olhares igualmente legítimos sobre a mesma realidade provavelmente é uma consequência do que Dennett (1998) chama de "reducionismo ganancioso"11.

[...] como a maioria das expressões ofensivas, "reducionismo" não tem um significado fixo. A imagem central é de alguém afirmando que uma ciência se "reduz" a outra: que a química se reduz à física, que a biologia se reduz à química, que as ciências sociais se reduzem à biologia, por exemplo. O problema é que existem, ao mesmo tempo, interpretações amenas e leituras grotescas para essa afirmação. De acordo com as interpretações amenas, é possível (e desejável) unificar a química com a física, a biologia com a química e, sim, até as ciências sociais com a biologia. Afinal de contas, as sociedades são compostas por seres humanos que, sendo mamíferos, devem obedecer aos princípios bi-

\footnotetext{
${ }^{11} \mathrm{Ou}$ reducionismo grosseiro, conforme o trecho citado abaixo.
} 
ológicos que incluem todos os mamíferos. Estes, por sua vez, são compostos por moléculas, que devem obedecer às leis da química, que por sua vez devem responder às regularidades da física subjacente. Nenhum cientista sensato questiona essa leitura amena; todos os tribunais de justiça juntos encontram-se tão unidos pela lei da gravidade quanto qualquer avalanche, porque também são, no final, uma coleção de objetos físicos. Segundo as interpretações grotescas, os reducionistas preferem abandonar os princípios, teorias, vocabulários e leis das ciências de alto nível usando termos inferiores. (DENNETT, 1998, p. 85)

O reducionismo ganancioso é uma posição que ninguém defende, mas inventada para que todos possam atacar: a tentativa vã e irremediavelmente equivocada de reduzir todas as ciências à física diante de uma espécie de frustração filosófica ao comparar outras disciplinas científicas ao sucesso preditivo da física. Ora, não faz sentido querer aplicar todos os métodos que funcionam na física para as outras disciplinas. Porém, o ataque ao reducionismo ganancioso não precisa nos levar ao extremo oposto de isolar as diversas disciplinas.

A física traz recursos epistemológi- cos para compreendermos a realidade, assim como a sociologia e a psicologia também trazem. Os instrumentais das diversas disciplinas científicas podem contribuir para a compreensão do funcionamento dessa mesma realidade. Por exemplo (DENNETT, 1991), podemos nos perguntar sobre porque rimos. Há várias respostas possíveis, cada uma parte de certa perspectiva e, embora diferentes, podem estar todas certas. Rimos por satisfação ou por ironia porque algo é engraçado, divertido, ridículo, ou mesmo porque estamos relaxados e ouvimos alguém rindo perto de nós. Mas talvez essa resposta não seja satisfatória para um psicólogo que quer explicar quais são os tipos de estímulos ambientais capazes de provocar risos nos seres humanos. A resposta a ser buscada pelo psicólogo também é relevante. Um neurologista pode querer pesquisar os eventos no cérebro quando rimos. Um antropólogo pode achar interessante estudar o que provoca riso dentro de uma comunidade específica e talvez não provoque riso em outra. São várias formas complementares de compreender o riso. Algumas permitem uma perspectiva de previsão mais acurada, mas nenhuma deve ser descartada.

Podemos utilizar a metáfora de um edifício, considerando os diversos ramos do saber humano como sendo erguidos uns sobre os outros, sendo que as ciências físicas estariam na base, as ciências da vida estariam sobre elas e as humanas, no topo. Assim, quanto mais 
as diversas disciplinas se aproximam da realidade social humana, mais complexas se tornam. Ainda que tomem como úteis e relevantes os conhecimentos produzidos pelas ciências de nível mais baixo, precisarão recorrer a novos instrumentais mais complexos para continuarem erguendo uma compreensão da realidade. Esse conhecimento será tanto mais multifacetado e terá tanto mais multiplicidades de bases epistemológicas concorrentes quanto mais no topo do edifício aquela disciplina estiver.

Provavelmente, nada há nesse tipo de abordagem que contradiga as ideias de Passeron, mas há uma diferença de ênfase. Aqui, pretende-se enfatizar que há os aspectos comuns capazes de nos trazer uma definição mais unificada de ciência, ao passo que a ênfase de Passeron está nas especificidades das disciplinas de ciências humanas, o que acaba por transformar as disciplinas em um arquipélago de ilhas isoladas entre si.

\section{Conclusão}

Este trabalho buscou aproximar as diversas disciplinas científicas por meio de três argumentos: uma recusa ampla do normativismo popperiano, uma discussão sobre o papel da linguagem natural em qualquer disciplina científica e a consideração da biologia como uma disciplina intermediária. Não há aqui a pretensão de oferecer um critério para a cientificidade. Buscou-se restaurar o aspecto da continuidade entre as diversas disciplinas científicas, considerando que somos seres sociais, mas também animais e corpos físicos.

Com isso, mesmo acolhendo a ideia de Passeron de que a concepção de ciência precisa ser alargada para incluir as ciências históricas, tenta-se organizar as disciplinas para diminuir as diferenças apontadas pelo autor entre ciências naturais e ciências históricas. Isso enfraquece a delimitação de Passeron entre ciências históricas e ciências naturais, embora provavelmente não afete o principal objetivo dele que é o de alargar a noção de ciência para nela poder incluir as ciências históricas.

Talvez, outra entrada para questão da relação entre as diversas disciplinas possa nos ajudar a iluminá-la. Nesse sentido, o trabalho propõe, a partir de Dennett $(1998 ; 2013)$, pensar sobre níveis de descrição da realidade. Há diversas formas de abordar a realidade que nos cerca e, em algumas ocasiões, algumas dessas formas são mais apropriadas do que outras. Nesse sentido, os vários métodos descritivos podem se aproximar, o que permitiria simplificar e organizar a tarefa de estabelecer critérios para as ciências empíricas.

A crítica a Passeron não se dirige aos aspectos mais centrais de seu trabalho. Sua afirmação de que as ciências históricas não se submetem à falsificação é acatada, assim como o papel mais fundamental que ele atribui às linguagens 
naturais para o fazer científico nas ciências humanas, dada a sua indexicalidade. O ponto de divergência é que ele parece estabelecer limites intransponíveis entre as disciplinas científicas, mas todas pretendem, na medida de suas possibilidades explicativas, tratar da mesma realidade. Portanto, talvez seja possível abrir um diálogo a partir da compreensão do que elas possuem em comum, construindo pontes no lugar de abismos.

\section{Referências}

ARRUDA, J. M. “Verdade, interpretação e objetividade em Donald Davidson”. Veritas. Porto Alegre, 2005, v. 50, n. 1, p. 137-154, mar. 2005.

CAMPBELL, D. "Blind variation and selective retention in creative thought as in other knowledge processes". Psychological Review, v. 67, n. 6, p. 380-400, 1960.

CHAlMERS, A. O que é ciência afinal? Tradução de Raul Filker. São Paulo: Editora Brasiliense, 1993. [Publicado originalmente em 1976.]

DENNETT, D. Consciousness explained. Londres: Penguin Books, 1991.

. A perigosa ideia de Darwin: a evolução e os significados da vida. Tradução de Talita M. Rodrigues. Rio de Janeiro: Rocco, 1998. [Publicado originalmente em 1995.]

Intuition pumps and other tools for thinking. New York; London: W. W. Norton \& Company, 2013.

GÓMEZ-TORRENTE, M. “Alfred Tarski”. ZALTA, E. (Ed.). The Stanford Encyclopedia of Philosophy (Spring 2015 edition). Disponível em: https://plato.stanford.edu/archives/spr2015/entries/tarski/. Acesso em 5 jan. 2017.

GOULD, S. J.; LEWONTIN, R. C. "The spandrels of San Marco and the Panglossian paradigm: a critique of the adaptationist programme". Proceedings of the Royal Society of London, v. 205, n. 1161, p. 581-598, 1979.

GRANGER, G. “À quoi servent les noms propres?” Langages, v. 16, n. 66, p. 21-36, jun. 1982.

HUANG, Y. Dictionary of pragmatics. Oxford: Oxford University Press, 2015.

KUHN, T. A estrutura das revoluções científicas. Tradução de Beatriz Vianna Boeira e Nelson Boeira. São Paulo: Editora Perspectiva, 1998.

LACOUR, P. "Critique de la raison symbolique et philosophie transcendantale". In: La nostalgie de l'individuel: essai sur le rationalism pratique de G. G. Granger. Paris: Libraire Philosophique J. Vrin, 2012, p. 91-123.

. O conhecimento clínico: do desafio às modalidades. [Notas de aula da disciplina de Tópicos especiais de Epistemologia do Programa de Pós-Graduação em Filosofia da UnB. 2016. Inédito.]

LAKATOS, I. Falsificação e a metodologia dos programas de investigação científica. Tradução de Emilia Picado Tavares Marinho Mendes. Lisboa: Edições 70, 1977.

LECLERC, A. "Linguagem e natureza na gramática universal clássica". In: MONTENEGRO, M. A.; PINHEIRO, C.; AZEVEDO, I. (Org.) Natureza e linguagem na filosofia. Fortaleza: Editora da UFC, 2008, p. 13-35.

"Princípios para uma semântica das línguas naturais: os clássicos e o novos". Perspectiva Filosófica. Recife, 2009, v. 11, n. 30, p. 11-33, fev. 2008 - jan. 2009.

PASSERON, J. C. O raciocínio sociológico: o espaço não-popperiano do raciocínio natural. Petrópolis: Vozes, 1995. [Tradução de Beatriz Sidou. Publicado originalmente em 1991.]

PEREBOOM, D. “Kant's transcendental arguments". ZALTA, E. (Ed.). The Stanford Encyclopedia of Philosophy (Fall 2014 edition). Disponível em : https://plato.stanford.edu/entries/kant-transcendental/. Acesso em 18 jan. 2917.

POPPER, K. A lógica da pesquisa científica. Tradução de Leonidas Hegenberg e Octanny Silveira da Mota. $16^{a}$ edição. São Paulo: Editora da Universidade de São Paulo, 2008. [Publicado originalmente em 1959.]

Recebido / Received: 03/10/2019

Aprovado / Approved: 30/03/2020

Publicado / Published: 20/09/2020 
